\title{
Formation of Vorticity of the Wind Speed Field in the Atmosphere over the Black Sea
}

\author{
V. V. Efimov*, A. V. Yurovsky \\ Marine Hydrophysical Institute, Russian Academy of Sciences, Sevastopol, Russian Federation \\ *e-mail: vefim38@mail.ru
}

\begin{abstract}
The spatial structure of the wind speed field vorticity in the Black Sea region over 1979-2013 period for January and July is considered. The data of high resolution regional reanalysis of the atmospheric circulation, obtained using the RegCM4 numerical model with input data of ERA-Interim reanalysis, were used. It is shown that in the western part of the sea the annual course of vorticity is determined by the monsoon mechanism which depends on the temperature contrasts between the sea and the surrounding land. In the eastern part of the sea cyclonic wind vorticity, determined by the contribution of the high mountains surrounding the sea, retains during a year. The variation of the wind speed vorticity by a height over the eastern and western parts of the sea is analyzed. It is concluded that the cyclonic vorticity in the main part of the troposphere is associated with global features of the atmospheric circulation as well as passing cyclones and anticyclones. In the lower part of the troposphere the vorticity is the result of the effect of both the monsoon mechanism and coastal orography. The contributions of the global and regional factors forming the wind speed field vorticity in the atmosphere surface layer are estimated.
\end{abstract}

Keywords: wind speed field vorticity, cyclone, anticyclone, monsoon mechanism, Black Sea.

DOI: 10.22449/1573-160X-2017-6-3-11

(C) 2017, V. V. Efimov*, A. V. Yurovsky

(C) 2017, Physical Oceanography

Introduction. One of the main mechanisms affecting the seasonal variability of the Black Sea water large-scale cyclonic circulation - the Black Sea Rim Current (BSRC) - is a near-water wind speed field vorticity related to the heat contrasts between the sea and surrounding land [1]. First assessments of the vorticity annual course related to the solar radiation seasonal course in the numerical model for the round sea are given in [2], the ones using ERA-40 reanalysis data are given in [3]. In [4] the refined assessments of near-water wind speed vorticity seasonal variation were obtained based on new data of atmospheric field numerical reanalysis with the increased resolution on the basis of $\operatorname{HadRM} 3 P$ model [5]. It was shown that the contrasts of buoyancy fluxes between the sea and surrounding land determine the monsoon mechanism of wind speed field seasonal variability and, correspondingly, wind stress vorticity, as well as the BSRC variability. A significant role of the mountains (surrounding the Black Sea) in the cyclonic vorticity formation in the eastern part of the sea was also shown. A recent paper [6] considers in detail a seasonal course of wind speed field vorticity and shows that it is the main factor determining the dynamics of the Black Sea waters.

Nevertheless, the fundamental question of large-scale global processes contribution to the seasonal variability remained unclear [7]. Two possible sources of near-water wind speed field vorticity can be pointed out among them. Firstly, this is synoptic process (cyclones and anticyclones) contribution to the formation of total resulting response of the wind speed field vorticity at the seasonal scales [8]. Thus, for example, the prevalence of cyclones entering the Black Sea region over 
anticyclones in terms of number and/or intensity may lead to a total cyclonic vorticity and vice versa (although quantitative assessments of their contribution to the vorticity are not known to us). The second possible mechanism is seasonal variations of global circulation such as meridional displacements of large-scale subtropical anticyclone position (the Black Sea region is situated at its northeastern flank) or the polar front displacements [2, 9]. They also can be considered as a cause for seasonal variations of near-water wind speed field variability. Thus, the ratio of global and regional factors in the formation of the near-water wind speed field vorticity over the Black Sea remains unclear and requires additional consideration.

The paper briefly discusses the main features of the wind speed field vorticity formation in the Black Sea region for the two seasons of the year and determines their differences in the eastern and western parts of the sea. Further, vertical profiles of the vorticity, allowing one to distinguish their changes in height, are analyzed. The ratio of global and regional mechanisms of the vorticity formation is also considered and their assessment for two parts of the sea is given.

The data. The work is based on the data of a new regional reanalysis of atmospheric circulation with an increased resolution using RegCM4 numerical model $[10,11]$ and the input data of ERA-Interim reanalysis [12, 13]. 18 vertical $\sigma$-levels are set in the model. The model has $25 \times 25 \mathrm{~km}$ spatial resolution, the input data for the surface are set with $1 \mathrm{~h}$ time step, for $\sigma$-levels $-6 \mathrm{~h}$. The calculations are carried out for 1979-2013 period which is half overlapping by the reanalysis [4].

The results. Averaged monthly mean fields of near-surface wind speed at $10 \mathrm{~m}$ height, the wind speed vorticity and the atmospheric pressure for the coldest (January) and for the warmest (July) months of the year are shown in Fig. 1. It should be pointed out that the shown fields are the result of averaging over a multiyear period for a certain month and the pattern of fields over certain time periods can significantly differ from the given one. The main feature of the averaged wind speed field for January is a large-scale circulation all over the Black Sea region, including the Sea of Azov. Air flow of north-north-western direction comes to the sea. At the same time, a cyclonic circulation strictly limited by the areas of the Black Sea and the Sea of Azov is formed throughout the Black Sea region. The Crimean Peninsula is located within the area of this large-scale cyclone without violating its general structure, on the whole. From the west the coast outlines the cyclone boundary, from the south and the east this circulation is bounded by high Pontic (2-3 km) and Caucasian (2-5 km) Mountains. They are a barrier preventing the marine air from getting into the adjacent land in winter period. An intensive air stream is formed along the Caucasian coast. Local areas related to the effect of the surface irregularities are formed immediately in the coastal regions [4]. Thus, over the entire water area of the Black Sea positive values of wind speed field vorticity and cyclonic circulation around the atmospheric pressure minimum are observed.

Summer atmospheric circulation significantly differs from the winter one. Essentially, the sea area can be divided into two parts along $34^{\circ} \mathrm{E}$ meridian passing across the narrowest place of the sea. In the eastern part the cyclonic vorticity remains, in the western one an area of anticyclonic circulation occurs. In general, air current in a planetary boundary layer of the entire Black Sea region is directed to 
the south. From the eastern part of the sea it still does not overcome and goes around the Caucasus Mountains and on the southern coast of the Black Sea it begins to overcome through the lower Pontic Mountains. Cyclonic vorticity area in the eastern part of the sea in summer-autumn period is a part of large cyclonic circulation in the center of which the Caucasian Mountains are situated. As it can be seen from the data of the initial ERA-40 reanalysis, this circulation is a part of more large-scaled one which includes the Caspian Sea and the Caucasian and Pontic Mountains in general. As for the winter period, local areas of anticyclonic vorticity directly adjacent to the high-mountain eastern and southern sea boundaries are pointed out.

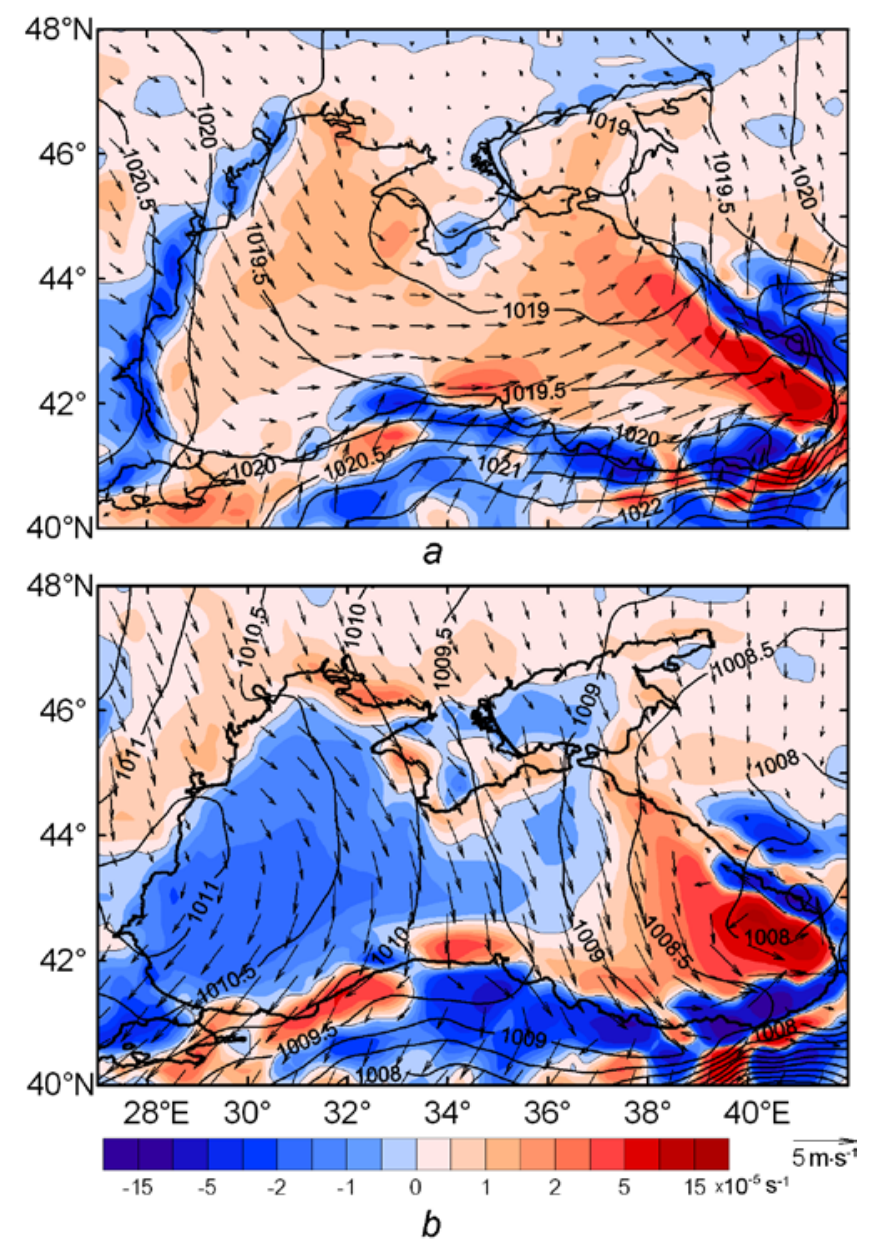

Fig. 1. The values, averaged over 1979-2013, of wind speed field vorticity (are indicated by color), wind speed vectors (arrows) at $10 \mathrm{~m}$ level and sea level pressure (isobars) in January ( $a$ ) and July (b)

The difference in the vorticity of wind speed field in the eastern and western sea parts conditionally divided by $34^{\circ} \mathrm{E}$ is explained by prevailing effect of high Caucasian Mountains in the eastern part. Seasonal course of vorticity in the western sea part in the absence of high surrounding mountains is almost entirely deter- 
mined by the monsoon effect, which has an annual periodicity. In the eastern part the contribution of high mountains to the vorticity in winter period intensifies the monsoon effect. In summer period this contribution prevails over the monsoon effect and, as result, generates a cyclonic circulation throughout the year. It should be noticed that the effect of the Caucasian Mountains on the cyclonic circulation development in the eastern sea part during the summer period is determined by features of baroclinic air flow interaction with the mountains. When the air overflows the northwestern edge of the Caucasian Mountains, it promotes the development of cyclonic circulation above the sea [14].

More detailed discussion of all features of wind speed field vorticity above the Black Sea related to the local regional manifestations of monsoon mechanism, coastal heterogeneities of the underlying surface and the effect of the surrounding high mountains was presented earlier in [4], based on data of another reanalysis PRECIS (albeit it is close in quality and the resolution the previously mentioned one) relating to 1958-2001 period. Particularly, a numerical experiment clearly illustrating the contribution of cyclonic or anticyclonic vorticity with regard to additional temperature contrasts of different signs between the sea and surrounding land was considered there. The results of these two regional reanalyses were found to be similar. Therefore, further the features of near-water wind speed fields, shown in Fig. 1, will not be considered, but we will focus on seasonal cycle of vorticity and its variation in height.

Wind vorticity annual course (averaged over the abovementioned areas of the Black Sea) on the surface and at $5 \mathrm{~km}$ height is shown in Fig. 2. For the western part of the sea where the impact of mountains is small and a well-pronounced cyclicity of heat contrasts between the sea and surrounding land prevails, near-water wind speed field vorticity also has a periodic character with a change of sign during a year. For the eastern part of the sea vorticity value remains positive during the entire year due to prevailing contribution of high Caucasian and Pontic Mountains. At $5 \mathrm{~km}$ height vorticity has different character of annual course: during the entire year $\sim(0.5-1) \times 10^{-5} \mathrm{~s}^{-1}$ cyclonic vorticity remains.

The distribution in height for wind vorticity values separately averaged for the western and the eastern parts of the Black Sea is given in Fig. 3. Seasonal variability of vorticity in the atmosphere near-water layer is most appreciable in the western part of the sea. As was mentioned above, orography has a small impact in this region and monsoon effect should be manifested in a purer form. Indeed, in the lower part of the troposphere at up to $2-3 \mathrm{~km}$ heights positive (cyclonic) vorticity for January and negative one (anticyclonic) for July are appreciable well. In the eastern part of the sea wind vorticity remains cyclonic all over the year.

At the heights which are more than 3-4 km in the both parts of the sea a behavior of vorticity vertical profiles changes: vorticity value increases again and reaches its maximum at $\sim 12-13 \mathrm{~km}$ heights. We may assume that within this range of heights an impact of local causes related to the surface heterogeneities (contrast of temperatures, orography, etc.) becomes small, and the key role is played by aforementioned global factors. At these heights in the both parts of the sea vorticity profiles, in general, change alike with the height, although some differences between them remain. 

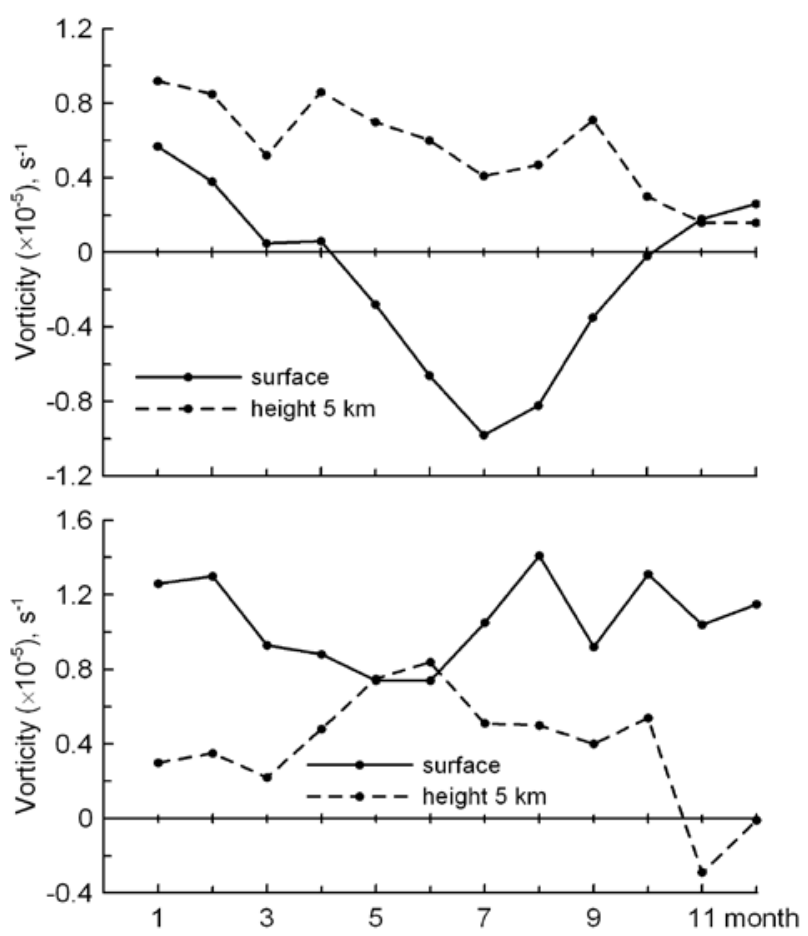

Fig. 2. Averaged annual course of wind speed field vorticity on the surface and at $5 \mathrm{~km}$ height in the western $(a)$ and eastern $(b)$ parts of the Black Sea

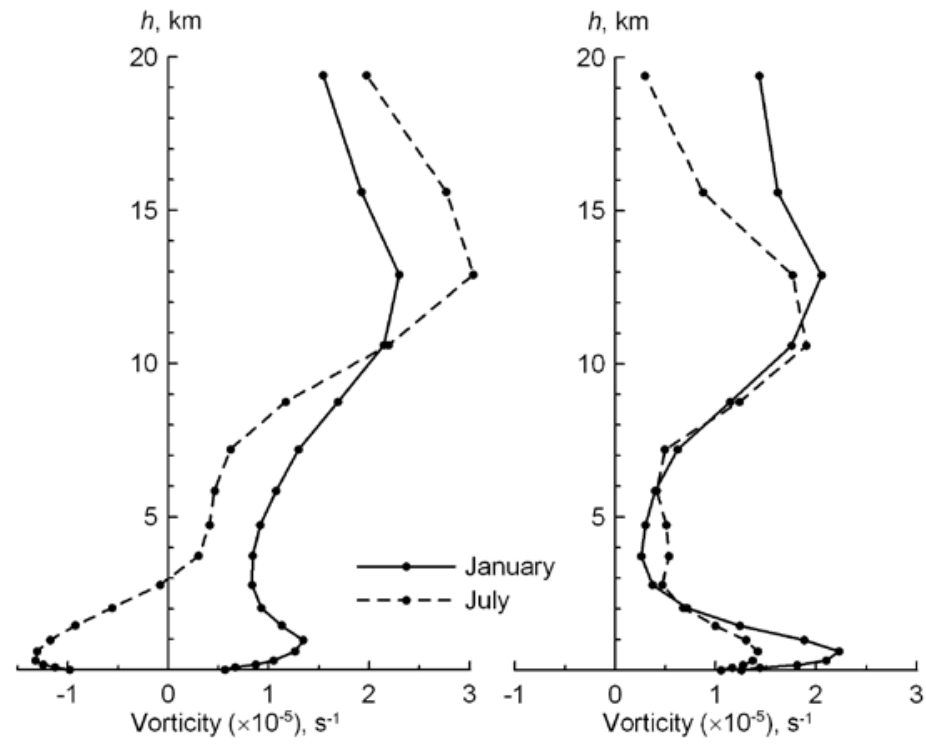

Fig. 3. Averaged distribution with the height of wind speed field vorticity in January and July for the western $(a)$ and eastern $(b)$ parts of the Black Sea

Wind field structure in the troposphere above the Black Sea at the heights which are more than $3-4 \mathrm{~km}$ is explained by Fig. 4 . Wind speed vectors and vorticity values at $5 \mathrm{~km}$ height are shown in it. The values of zonal speed gradients PHYSICAL OCEANOGRAPHY ISS. 6 (2017) 
characterizing a meridional heterogeneity of zonal flux and meridional speed gradients describing the zonal flux curvature are two summands of vorticity. They are represented well in Fig. 4: pronounced western zonal transport in mid-troposphere, variations of its meridional gradients in a seasonal course as well as a curvature of zonal flux. Detailed analysis of wind speed fields in the troposphere and the causes for the occurrence of differences between the vorticity profiles in different parts of the sea is beyond the scope of this work and requires a more general consideration of the features of global circulation throughout the region. It can only be concluded that probably the main cause for small differences in the vorticity profiles for both parts of the sea is an impact of the high Caucasian and Pontic Mountains. Disturbances caused by them are recorded at 5 km height and can be clearly seen in Fig. 4 .

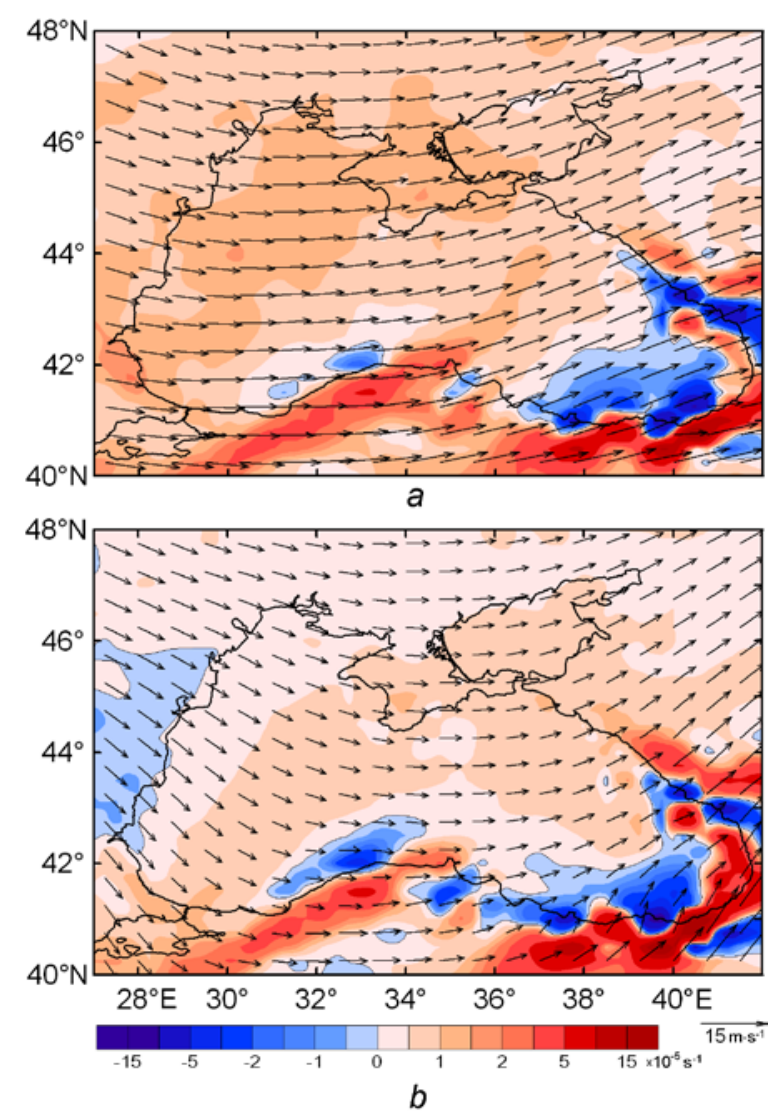

Fig. 4. Averaged values of wind speed field vorticity (indicated by color) and wind speed vectors at $5 \mathrm{~km}$ height in January ( $a$ ) and July (b)

Thus, an abrupt difference in vorticity vertical profiles in the lower part of the atmosphere and at the heights of over $2-3 \mathrm{~km}$ directly indicates that the vorticity in near-water layer is a result of regional processes - monsoon and orographic ones. At high altitudes vorticity has mainly global nature related to the features of largescale circulation [15]. Here cyclonic vorticity persists throughout a year. 
It should be pointed out that the problem of intensive synoptic structures (cyclones and anticyclones) direct contribution to the total monthly average value of near-water wind speed field vorticity remains unclear. We also note that for the western part of the sea, in the region of the vorticity profile minimum at heights of $\sim 5 \mathrm{~km}, \sim 10^{-5} \mathrm{~s}^{-1}$ positive vorticity remains in the winter period. This indicates a coherence of vorticity formation processes in the upper and lower parts of the troposphere in this season. Synoptic eddies can be a reason for this coherence, which provide an additional contribution to the total value of wind speed field vorticity on the surface.

Physical nature of this fact is explained by Fig. 5, in which the histograms of 6-hour values of sea level pressure for one of the points in the center of the western sea part are shown. As is obvious, for summer period root-mean-square value of pressure pulsations is $4.16 \mathrm{hPa}$, and asymmetry is small and makes up $\sim-0.19$. For winter period both root-mean-square deviation and asymmetry are 2 times higher. This indicates that the contribution of synoptic cyclones and anticyclones to the total value of pressure in summer is relatively small in comparison with the one in winter. The situation changes in winter: a larger negative modulus of asymmetry indicates that the contribution of cyclones is greater than that of anticyclones.

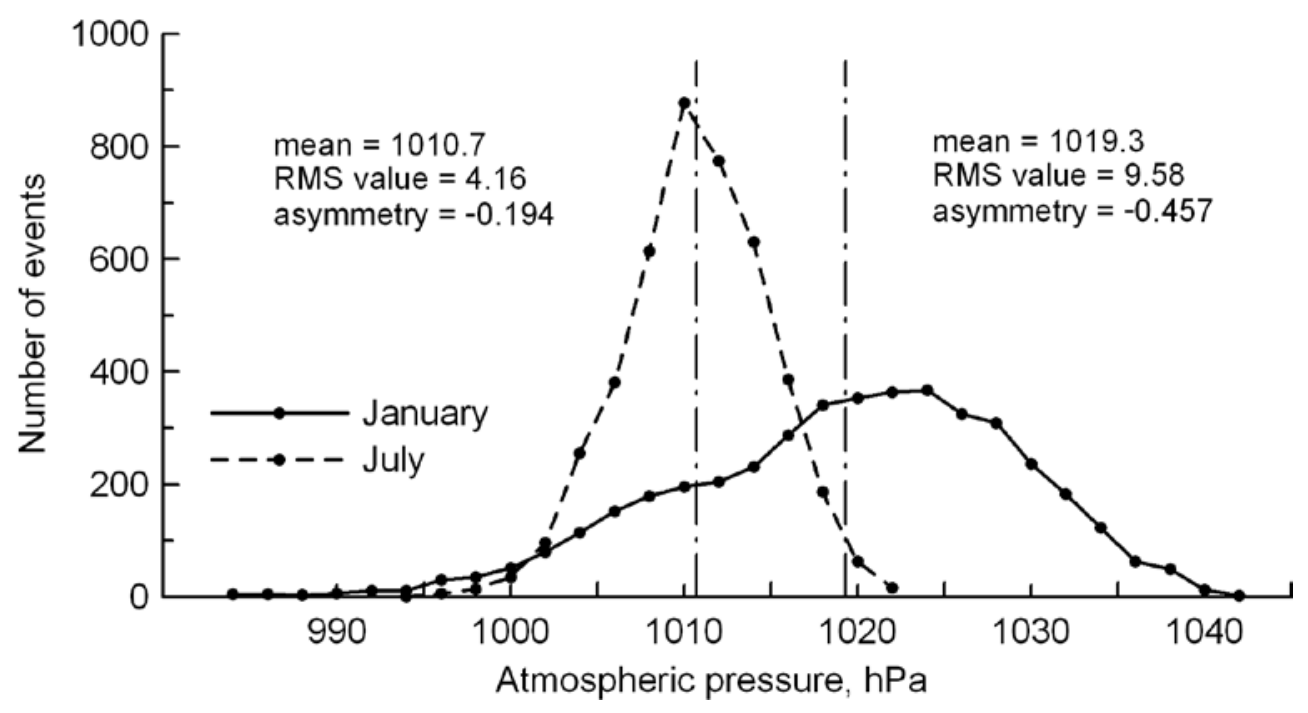

Fig. 5. Histograms of distribution of 6-hour sea level pressure in January and July 1979-2013 in the Black Sea western part $\left(44^{\circ} \mathrm{N}, 31^{\circ} \mathrm{E}\right)$

However, it is still difficult to separate the contribution of synoptic eddies and large-scale circulation to the vorticity. A rough assessment of these two global mechanisms total contribution to the formation of near-water wind vorticity can be obtained on the basis of the data given in Fig. 1, 2, 4. For January, averaged values of speed and vorticity decrease from $10-15 \mathrm{~m} \cdot \mathrm{s}^{-1}$ at $5 \mathrm{~km}$ height down to $3-5 \mathrm{~m} \cdot \mathrm{s}^{-1}$ values of near-surface speed (i.e. approximately in three times) as approaching to the surface. As a result, in the first approximation we can assume that global vorticity at $5 \mathrm{~km}$ height $\left(\sim 0.9 \times 10^{-5} \mathrm{~s}^{-1}\right)$ will also decrease in proportion to the speed PHYSICAL OCEANOGRAPHY ISS. 6 (2017) 
and will be equal to $\sim 0.3 \times 10^{-5} \mathrm{~s}^{-1}$ for the near-water wind. This makes up about a half of the near-water wind vorticity total value $\left(0.6 \times 10^{-5} \mathrm{~s}^{-1}\right)$ shown in Fig. 2 . Thus, we can associate $\sim 50 \%$ of cyclonic vorticity in winter period for the western part of the sea with the direct contribution of averaged global circulation and cyclones passing above the Black Sea water area. For the eastern part of the sea this contribution to the vorticity total value is equal to $\sim 25 \%$.

For other seasons this ratio changes. In spring and autumn temperature contrasts between the sea and the land and, correspondingly, the values of near-water wind vorticity values in the western part of the sea are rather small, as is obvious from Fig. 2. In summer synoptic anticyclones, as well as global circulation, cannot contribute to the total anticyclonic vorticity: distribution asymmetry for it is negative and rather small. In the main part of the troposphere the vorticity above the Black Sea remains cyclonic throughout a year. Therefore, near-surface wind anticyclonic vorticity in the western part of the sea is totally due to monsoon effect.

Conclusion. Spatial structure of near-water wind speed and sea level pressure for January and July are considered. The difference of seasonal variability of wind speed field vorticity in western and eastern parts of the Black Sea is shown. In the western part vorticity is determined by the monsoon mechanism depending on cyclical annual course of temperature contrasts between the sea and surrounding land. In the eastern part cyclonic vorticity of wind speed field controlling by the contribution of high mountains which surround the sea remains.

The variation in height of wind speed field vorticity above the eastern and the western parts of the sea is considered. It is shown that vorticity profiles in the lower part of the atmosphere, to $2-3 \mathrm{~km}$ and higher, are different and this indicates the difference of vorticity formation physical mechanisms in these layers. In the main part of the troposphere, the vorticity has a cyclonic character throughout a year. This character is related to the global features of atmosphere circulation and passing synoptic cyclones. In the lower part, at the heights below $2-3 \mathrm{~km}$, vorticity is a result of monsoon mechanism and coastal orography effect.

The assessment of contribution ratio of global and regional factors forming wind speed field vorticity in the near-water layer is given. In winter month the contribution of global causes can be up to a half of near-water vorticity total value, for the eastern one - about a quarter. In summer, aticyclonic vorticity in the western part is totally determined by the monsoon mechanism. Vorticity formation in the eastern part during the entire year is mainly affected by high surrounding mountains. As a result, in summer the vorticity also remains cyclonic.

Acknowledgements. The research was carried out within the framework of State Order No. 0827-2015-0001 «Fundamental research of the processes in the ocean - atmosphere - lithosphere system determining spatial-temporal variability of the global and regional scale environment and climate» («Climate» code).

\section{REFERENCES}

1. Blatov, A.S., Bulgakov, N.P., Ivanov, V.A., Kosarev, A.N. and Tujilkin, V.S., 1984. Izmenchivost' Gidrofizicheskikh Poley Chernogo Morya [Variability of Hydrophysical Fields in the Black Sea]. Leningrad: Gidrometeoizdat, 240 p. (in Russian). 
2. Korotaev, G.K., 2011. O Prichine Sezonnogo Khoda Tsirkulyatsii Chernogo Morya [On the Cause of the Black Sea Circulation Annual Course]. Morskoy Gidrofizicheskiy Zhurnal, (6), pp. 14-20 (in Russian).

3. Efimov, V.V., Shokurov, M.V. and Barabanov, V.S. 2002. Physical Mechanisms of Wind Circulation Forcing over the Inland Seas. Izv. Atmos. Ocean. Phys., 38(2), pp. 217-228.

4. Efimov, V.V. and Anisimov, A.E., 2011. Climatic Parameters of Wind-Field Variability in the Black Sea Region: Numerical Reanalysis of Regional Atmospheric Circulation. Izv. Atmos. Ocean. Phys., [e-journal] 47(3), pp. 380-392. https://doi.org/10.1134/S0001433811030030

5. Jones, R.G., Noguer, M., Hassell, D.C., Hudson, D., Wilson, S.S., Jenkins, G.J. and Mitchell, J.F.B., 2004. Generating High Resolution Climate Change Scenarios Using PRECIS. Exeter, UK: Met Office Hadley Centre, 40 p.

6. Kubryakov, A., Stanichny, S., Zatsepin, A. and Kremenetskiy, V., 2016. Long-term Variations of the Black Sea Dynamics and Their Impact on the Marine Ecosystem. J. Mar. Syst., [e-journal] 163, pp. 80-94. doi:10.1016/j.jmarsys.2016.06.006

7. Stanev, E.V., 2005. Understanding Black Sea Dynamics: Overview of Recent Numerical Modeling. Oceanography, [e-journal] 18(2), pp. 56-75. doi:10.5670/oceanog.2005.42

8. Artamonov, Yu.V., Belokopytov, V.N. and Skripaleva, E.A., 2006. Sezonnaya Dinamika Krupnomasshtabnykh Tsiklonicheskikh Krugovorotov Chernogo Morya [Seasonal Dynamics of Large-Scale Cyclonic Gyres of the Black Sea]. In: MHI NANU, 2006. Sistemy Kontrolya Okruzhayushchey Sredy [Environmental Control Systems]. ECOSI-Gidrofizika, pp. 268-270 (in Russian).

9. Zatsepin, A.G., Kremenetskiy, V.V., Poyarkov, S.G., Ratner, Yu.B. and Stanichny, S.V., 2002. Vliyanie Polya Vetra na Tsirkulyatsiyu Vod Chernogo Morya [Influence of Wind Field on Water Circulation in the Black Sea]. In: A.G. Zatsepin, M.V. Flint, eds., 2002. Kompleksnye Issledovaniya Severo-Vostochnoy Chasti Chernogo Morya [Multidisciplinary Investigations of the Northeast part of the Black Sea]. Moscow: Nauka, pp. 91-105 (in Russian).

10. Giorgi, F. and Anyah, R.O., 2012. The Road towards RegCM4. Clim. Res., [e-journal] 52, pp. 3-6. doi:10.3354/cr01089

11. Anisimov, A.E., Yarovaya, D.A. and Barabanov, V.S., 2015. Reanalysis of Atmospheric Circulation for the Black Sea-Caspian Region. Physical Oceanography, [e-journal] (4), pp. 14-28. doi:10.22449/1573-160X-2015-4-13-25

12. Uppala, S.M., Kållberg, P.W., Simmons, A.J., Andrae, U., Bechtold, V.D., V., Fiorino, M., Gibson, J.K., Haseler, J. and Hernandez, A. [et al], 2005. The ERA-40 Re-analysis. Q. J. R. Meteorol. Soc., [e-journal] 131(612), pp. 2961-3012. doi:10.1256/qj.04.176

13. Dee, D.P., Uppala, S.M., Simmons, A.J., Berrisford, P., Poli, P., Kobayashi, S., Andrae, U., Balmaseda, M.A. and Balsamo, G. [et al], 2011. The ERA-Interim Reanalysis: Configuration and Performance of the Data Assimilation System. Q. J. R. Meteorol. Soc., [e-journal] 137(656), pp. 553-597. doi:10.1002/qj.828

14. Efimov, V.V. and Mikhaylova, N.V., 2017. The Mesoscale Atmospheric Vortex as a Manifestation of the Novorossiysk Bora. Izv. Atmos. Ocean. Phys., [e-journal] 53(4), pp. 449-458. doi:10.1134/S000143381704003X

15. Palmén, E. and Newton, C.W., 1969. Atmospheric Circulation Systems. Their Structural and Physical Interpretation. New York: Academic Press, 606 p. 